\title{
«E1 Sol es comido»: representaciones, prácticas y simbolismos del eclipse solar entre los antiguos nahuas y otros grupos mesoamericanos
}

\author{
Jaime ECHEVERRÍA GARCÍA \\ Instituto de Investigaciones Históricas, Universidad Nacional Autónoma de México \\ jecheverriagarcia@yahoo.com
}

Recibido: 9 de julio de 2013

Aceptado: 1 de octubre de 2014

\begin{abstract}
RESUMEN
El artículo tiene como objetivo explicar las concepciones del eclipse solar entre los nahuas prehispánicos, a través de las fuentes escritas y pictóricas coloniales. Si bien el punto de partida son los antiguos nahuas y el mayor corpus de información proviene de ellos, existe un fuerte apoyo en la información maya, tanto antigua como presente, así como en las etnografías de diversos grupos indígenas contemporáneos, y el propio trabajo de campo del autor entre los nahuas de Pahuatlán, en la Sierra Norte de Puebla. De esta manera, se ofrece una visión amplia del fenómeno. Los aspectos que se abordan en el trabajo son las representaciones del eclipse de Sol, los agentes que intervinieron en él, las prácticas rituales implementadas por los nahuas y otros grupos para aminorar el ataque que sufría el astro, así como los efectos nocivos que producía el eclipse. Por último, se propone una hipótesis del eclipse solar de carácter simbólico, basada principalmente en datos etnográficos.
\end{abstract}

Palabras clave: Sol, eclipse, prácticas rituales defensivas, nahuas, Mesoamérica.

\section{«The Sun Is Eaten»: Representations, Practices, and Symbolisms of Solar Eclipse among Ancient Nahuas and Other Mesoamerican Groups}

\begin{abstract}
This article is aimed at explaining the conceptions of the eclipse of the sun among prehispanic Nahuas, through the colonial written and pictorial sources. Although the starting point are ancient Nahuas and the main corpus comes from them, there is a strong support in ancient as well as present day Mayan data. Such support is also found in ethnographies of various contemporary Indian groups, and my own field work among Nahuas of Pahuatlan, in Sierra Norte de Puebla. Thus, it is offered a big picture of this phenomenon. The article explains the way in which an eclipse of the sun was represented, the various agents involved in it, the ritual practices implemented by Nahuas and other ethnic groups to reduce the attack suffered by this luminary, as well as the damaging effects produced by the eclipse. At the end, a hypothesis is advanced of the symbolical nature of an eclipse, based mainly on ethnographic data.
\end{abstract}

Key words: Sun, eclipse, defensive ritual practices, Nahuas, Mesoamerica.

Sumario: 1. Introducción. 2. Conceptos, representaciones y agentes del eclipse solar. 3. Prácticas defensivas contra el eclipse solar. 4. Consecuencias funestas del eclipse de Sol. 5. Eclipse de Sol, ceguera, transgresión y castigo. 6. Conclusiones. 7. Referencias bibliográficas.

\section{Introducción}

El conjunto de datos -tanto escritos como pictóricos- que disponemos para estudiar el fenómeno del eclipse solar entre los antiguos nahuas es relativamente abundante. No obstante, como ocurre al investigar casi cualquier aspecto de la cultura prehispánica, nos encontramos con lagunas de información en la documentación colonial que nos impiden realizar una cabal reconstrucción de nuestro tema de estudio. Para paliar esta deficiencia, el estudioso puede recurrir a la comparación con otros materiales de la época pertenecientes a otro grupo indígena y a la analogía etnográfica. 
En mi estudio sobre las creencias del eclipse de Sol entre los nahuas prehispánicos he recurrido, en buena medida, a la información maya colonial y contemporánea pero también de otros grupos-, lo que me ha permitido avanzar en la explicación e interpretación del fenómeno. A través de la comparación de prácticas referentes al eclipse entre los antiguos nahuas y grupos indígenas contemporáneos, igualmente nahuas y de otro origen étnico, nos percatamos de la unidad de pensamiento que existió y existe entre las diversas culturas mesoamericanas. A la vez, en las diferencias observamos algunas de las particularidades de cada una de dichas culturas o de algunas de ellas.

A lo largo del texto, especialmente a partir del apartado «Consecuencias funestas del eclipse de Sol», recurro con mayor énfasis a la analogía y la extrapolación entre la información contemporánea y la histórica, pero por ningún motivo pretendo hacer pasar los datos de una cultura como propios de otra. Los desplazamientos que se hacen entre los materiales antiguos y los presentes los justifico con base en la unidad cultural de Mesoamérica y su larga duración, que no se vio interrumpida por la dominación colonial y que ha persistido hasta nuestros días; sin embargo, no dejo de reconocer las variadas transformaciones que han sufrido los contenidos ideológicos indígenas. Habiendo expuesto lo anterior, comienzo con una breve exposición sobre la importancia que tenía el astro solar en el pensamiento de los antiguos nahuas.

El astro diurno era el punto de referencia a partir del cual se establecía el orden en el mundo: su creación inauguraba el dominio sobre las tinieblas perpetuas, y su destrucción la vuelta al caos primigenio. Pero también a través del origen del Sol se establecía la necesaria alternancia de los principios opuestos, la periodicidad del tiempo que aseguraba el paso de la noche al día, de la oscuridad a la luz, del caos al orden, el equilibrio entre lo acuoso y lo ígneo, el principio femenino y el masculino (véase Graulich 1988: 394).

El mito narra que una vez que el Sol salió por el este al ser creado a partir de su inmolación por fuego, no se movía, y al verlo los dioses mandaron a Tlotli (gavilán) para que le dijera que hiciera su curso, pero el Sol respondió que no se movería hasta que todos los dioses murieran. Después de que Citli trató de hacerlo mover lanzándole flechas, lo que motivó su muerte por el astro, los dioses se espantaron y vieron que no podían prevalecer sobre el Sol, por lo que decidieron sacrificarse. Xolotl se encargó de ello abriéndoles a todos el pecho con un pedernal, para después sacrificarse él. Así fue aplacado el astro diurno y comenzó su curso (Mendieta 2002: t. I, lib. II, cap. II, 183-184; Torquemada 1975: t. III, lib. VI, cap. XLIII, 122) ${ }^{1}$. De igual manera, en la Historia de los mexicanos por sus pinturas (2002: cap. VI, 39) se asienta que la

\footnotetext{
1 Otra versión muy similar cuenta que una vez que fue creado el astro se quedó inmóvil por cuatro días. Los dioses mandaron igualmente al gavilán (itztlotli) para que fuera a preguntarle por qué no se movía, y éste respondió: «porque estoy pidiendo su sangre, su vigor y su servicio». Entonces los dioses se convocaron. Tlahuizcalpantecuhtli se enojó y lo flechó, pero no logró darle, mientras que el Sol lo flechó a él. Las deidades se reunieron y se sacrificaron en Teotihuacan (Leyenda de los Soles 2002: 183, 185). Una tercera versión sobre la inmovilidad del Sol, pero que no implica sacrificio de sangre, narra que una vez que fue creada la tercera edad el astro solar no se movía, por lo que el mosquito le preguntó por qué no hacía su oficio tal como se le había mandado, que si quería destruir el mundo. Viendo el mosquito que no le respondía le picó una pierna, y así retomó su curso el Sol (Alva Ixtlilxochitl 1997: t. I, 264).
} 
condición necesaria para que el Sol tuviera movimiento era que «comiese corazones y bebiese sangre».

El ofrecimiento de sangre para impulsar el recorrido diario del astro diurno era una tarea colectiva de la que participaban los guerreros, los sacrificados y el pueblo, en general. De esta manera, el Sol era la única deidad a la que se le ofrendaba diariamente (véase González Torres 1975: 83; Sahagún 2002: t. I, apéndice libro II, 292-293). Al salir el astro por la mañana la gente se punzaba las orejas y le ofrecía su sangre, así como la sangre de codornices que eran descabezadas y luego elevadas al Sol mientras se desangraban. Posteriormente, se dirigían al astro y le pedían que hiciera prósperamente su oficio. También le ofrecían copal cuatro veces al día, que abarcaba desde que el astro diurno despuntaba hasta que llegaba a su ocaso; y cinco veces en la noche (Sahagún 2002: t. I, apéndice libro II, 292).

Debido a la ausencia del astro solar durante la noche, dicho tiempo de oscuridad se veía de especial desprotección porque las fuerzas nocturnas y malignas podían manifestarse y acechar al ser humano. Era el momento en que aparecían en el firmamento las estrellas que no se veían por la luz solar, las cuales se identificaron con las tzitzimime (Seler 1980: t. I, 139). También era el tiempo propicio para la aparición de seres sobrenaturales, como algunas advocaciones de Tezcatlipoca (Códice Florentino, lib. V, en Sahagún 1969: 21, 28-29, 50-51, 53).

Asimismo, sabían que durante el día podían surgir amenazas contra el astro, por ejemplo, un eclipse, por lo que le ofrendaban el bien más preciado con el fin de darle vitalidad y fuerza para enfrentar cualquier peligro durante su recorrido. Así como el eclipse representaba un atentado contra el astro, dicho momento crítico ponía en riesgo a toda la humanidad. Otra crisis del Sol surgía cada 52 años durante la ceremonia del Fuego Nuevo, en la cual existía el riesgo de que el astro no volviera a salir de no encenderse el fuego ${ }^{2}$.

\section{Conceptos, representaciones y agentes del eclipse solar}

El principal peligro que enfrentaba el Sol era ser devorado, tal como lo refieren los sintagmas nahuas tonatiuh qualo, oqualoc in tonatiuh, iqualoca in tonatiuh (Molina 2004: sección español-náhuatl, fol. 48r), «el Sol es comido», «fue comido el Sol», «había sido comido el Sol», respectivamente; teotl qualloz, «el dios será comido» (Anales de Cuauhtitlan 1945: 86, nota 121); motlapacho tonatiuh (Libro de los guar-

\footnotetext{
2 Otro tiempo delicado proporcionado por la etnografía es la presencia de una circunferencia que rodea al sol en ciertos momentos, la cual es nombrada tecal Dios, «la casa de Dios», por los nahuas de Mamiquetla. Este hecho, según ellos y sus vecinos xolotecos, indica que el sol está enfermo, estado patológico que se proyecta en las personas, pues es augurio de enfermedades como disentería, diarrea y vómito, así como de epidemias. Otra interpretación de tal signo es la abundancia de lluvias y los consiguientes desgarres de cerros. Todas las referencias a las comunidades nahuas de Xolotla y Mamiquetla, pertenecientes al municipio de Pahuatlán, en la Sierra Norte de Puebla, fueron recuperadas por el autor durante tres estancias realizadas en 2010. Agradezco a Don Beto Hernández Casimira, de Xolotla, y a Cristina González, quien reside en Mamiquetla, por la información que me proporcionaron.
} 


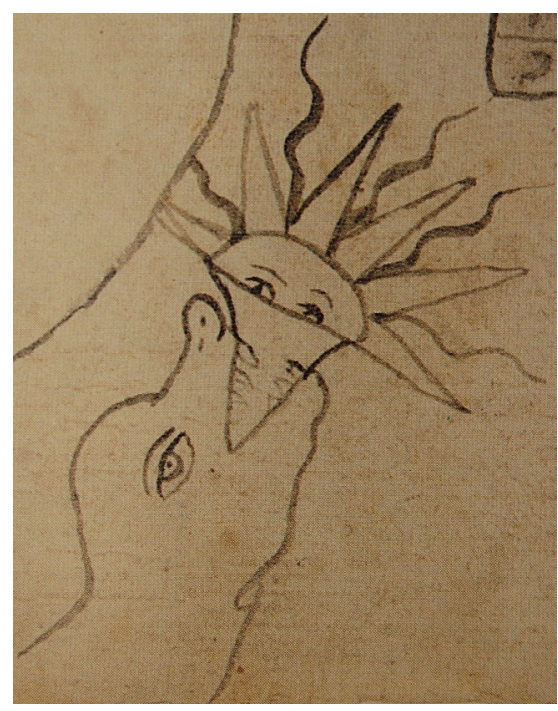

Figura 1: Tecuani que devora al sol (Códice Azcatitlan 1995: lám. 5).

dianes... 1995: 84-85), «se cubrió el Sol» ${ }^{3}$; y oqualoc yn tonatiuh otlayohua (Códice de Huichapan 2003: fols. 14, 38, 60), «fue comido el Sol, se oscureció»».

En teoría, los conceptos anteriores debieran tener su correspondencia iconográfica. Se esperaría que la representación del eclipse fuera la del astro solar siendo devorado. La lengua náhuatl nos proporciona un certero candidato para esta acción: el tecuani, literalmente, «el que come gente». Este concepto abarca a las fieras que muerden y a cualquier animal ponzoñoso (Molina 2004: sección españolnáhuatl, fol. 21r; sección náhuatl-español, fol. 104v). Precisamente, en el Códice Azcatitlan (1995: lám. 5) se muestra la escena de un eclipse de Sol siendo devorado por un bestia (véase Aguilera y Galindo 1991: 61). De acuerdo con Robert Barlow (en Códice Azcatitlan 1995: II, 78), ésta corresponde a una culebra, reptil igualmente considerado tecuani (Molina 2004: sección español-náhuatl, fol. 19v) (Figura 1).

Lo anterior trae a la memoria el Monolito del jaguar ubicado en el sitio matlatzinca de Teotenango, en el Estado de México, que fue conquistado por los mexicas durante el Posclásico Tardío. Este monolito fue labrado en bajorrelieve en una gran roca que aflora en uno de los muros del lado oriental del conjunto A, y en él se representa a un jaguar en posición sedente, que con sus fauces abiertas engulle un objeto que ha sido identificado como un corazón, el cual es sostenido entre sus garras delanteras. Un dato relevante es que en su muslo derecho tiene la imagen de un fémur (Álvarez 1983: 244) ${ }^{4}$. Chavero (1951, citado por Álvarez 1983: 244) interpretó la escena como un eclipse solar: el jaguar, identificado con la luna por medio del fémur, devora al Sol-corazón (Figura 2). Hay que recordar que el vocablo nahua metztli refiere tanto a pierna, que corresponde al fémur, como a Luna (Molina 2004: sección náhuatlespañol, fol. 55v).

De acuerdo con Lehmann (1968: 32), se pensaba en jaguares que atravesaban en la oscuridad y se tragaban la luz. Al respecto, las fuentes vinculan el eclipse de Sol con los jaguares al narrar la destrucción del Sol Yohualtonatiuh, pero no se menciona

\footnotetext{
3 El verbo tlapachoa.nino, «cubrirse con algo» (Molina 2004: sección náhuatl-español, fol. 130v), indica que algo cubre al Sol, lo que correspondería al agente del eclipse.

4 En el libro Cronología y astronomía maya-mexica (con un anexo de historias indígenas), Alberto Escalona (1940: 250) incurrió en varios errores al describir la figura del Monolito del Jaguar así como su localización. Él mencionó que este petrograbado se encontraba en el cerro de San Joaquín en Tenango, pero en realidad se encuentra en el cerro Tetepetl, sobre el cual se erige el sitio arqueológico de Teotenango, que pertenece al municipio de Tenango del Valle. Por otro lado, describió al jaguar como una figura femenina con cola y cabeza de itzcuintli u ocelotl, cuando tal figura no posee más rasgos que los del propio felino. Esta misma información fue reproducida por Yólotl González (1975: 86) en su texto El culto a los astros entre los mexicas.
} 


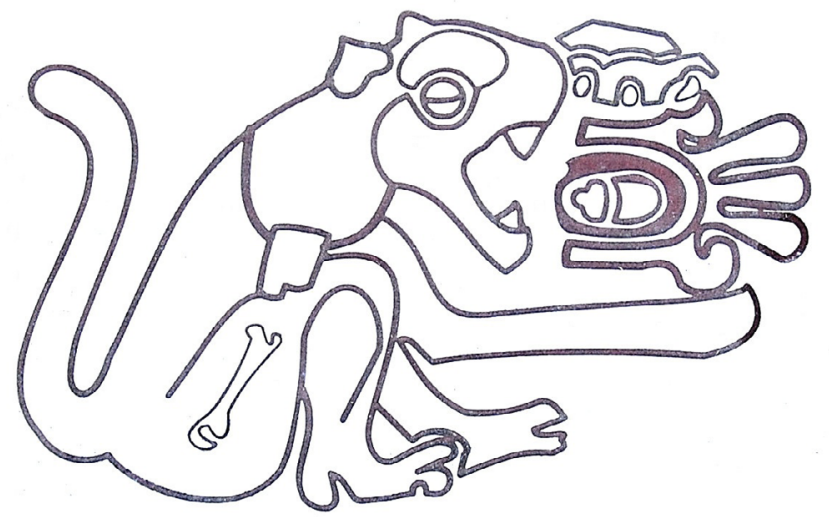

Figura 2: Bajorrelieve del Monolito del jaguar. Zona arqueológica de Teotenango.

que éstos fueron los causantes del eclipse, pues se dice que al momento en que se oscureció el astro solar, los jaguares empezaron a devorar a los gigantes (Anales de Cuauhtitlan 1945: 5). Sin embargo, la iconografía demuestra que el jaguar sí intervino en el ataque al Sol, como se acaba de exponer.

En contraste con la forma de representación anterior, la obra sahaguntina muestra imágenes de eclipse de clara influencia europea. En los Primeros Memoriales (Sahagún 1997: fol. 282r) hay dos imágenes de eclipses - una de Sol y otra de Luna- en las que el Sol está pintado combinando la manera tradicional indígena y la forma occidental, en tanto que la luna se representa muy occidentalizada. Aquí, el daño al Sol se presenta como una especie de aspiración de éste por la Luna. Mientras que en el Códice Florentino (Florentine Codex 1950-82: lib. VII), elaborado 30 años después, se pintó un eclipse donde aparecen los dos astros con un carácter renacentista (Aguilera y Galindo 1991: 61).

Una forma recurrente de representar el eclipse en los códices Telleriano-Remensis (1964: t. I, parte III, lám. XV, 288; lám. XXV, 308; lám. XXVI, 310) (Figura 3a) y Vaticano Latino 3738 (1964: t. III, lám. CXVII, 254; lám. CXXIX, 278), es mediante la figura del astro solar a la manera indígena con la ausencia de una parte de éste, lo cual indica que el agente del eclipse se la «comió». Una variante de esta forma de representación es la que muestra al Sol mordido con la aparición de las estrellas, y en la parte superior de la imagen vírgulas de humo (Códice Telleriano-Remensis 1964: t. I, parte III, lám. XXIX, 316) (Figura 3b).

Otra manera es el dibujo del disco solar, también a la usanza indígena, con la superposición de la Luna -a la manera europea-sobre aquél en uno de sus extremos, mientras que aparece el cielo estrellado como fondo (Códice Telleriano-Remensis 1964: t. I, parte III, lám. XXII, 302; también Códice Vaticano Latino 3738 1964: t. III, lám. CXXIV, 268) (Figura 3c).

Estas representaciones, aunque en parte europeizadas, corresponden con la interpretación tlaxcalteca del eclipse: el combate que entablaban el Sol y la Luna (Muñoz Camargo 1998: 149). Y como se vio en el petrograbado de Teotenango, el jaguarLuna ataca (devora) al Sol. Con base en lo anterior, se puede afirmar que el eclipse solar se originaba por un ataque al Sol ocasionado por la Luna, la cual podía tomar la forma de un jaguar -o posiblemente de otro tecuani, como la serpiente- con el fin 

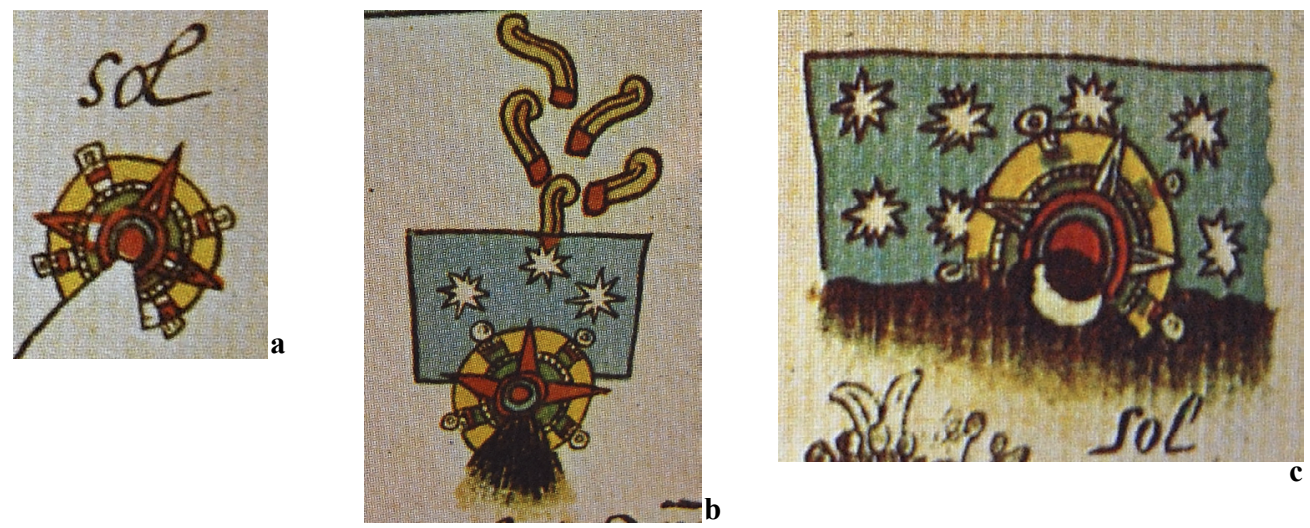

Figura 3: Representaciones prehispánicas del eclipse solar; $a$ : mediante la representación del astro (Códice Telleriano-Remensis 1964: t. I, parte III, lám. XV, 288); b: con cielo estrellado y vírgulas de humo (Códice Telleriano-Remensis 1964: t. I, parte III, lám. XXIX, 316); c: representación con influencia europea (Códice Telleriano-Remensis 1964: t. I, lám. XXII, 302).

de comer a aquel astro. O bien, la acción devoradora que desempeñaba la Luna pudo propiciar su representación como tecuani, lo que considero más acertado.

Los nahuas tlaxcaltecas también creían que los dos astros eran marido y mujer (Muñoz Camargo 1998: 148). Otra fuente indica que la Luna siempre andaba tras el Sol, pero nunca lo alcanzaba (Historia de los mexicanos por sus pinturas 2002: cap. XXI, 81). El texto yucateco del Libro de Chilam Balam de Chumayel (1985: 67) explica de manera similar el origen del eclipse: «A los hombres les parece que a sus lados está ese medio círculo en que se retrata cómo es mordido el Sol [...]. Lo que lo muerde, es que se empareja con la Luna, que camina atraída por él, antes de morderlo».

La creencia de que el eclipse se origina por el combate de los astros diurno y nocturno está ampliamente extendida entre los grupos indígenas contemporáneos, tales como los quichés, cakchiqueles, tzeltales -y otros grupos mayas-(Nájera 1995: 325), totonacos (Ichon 1973: 66), y nahuas de Xolotla. Para los nahuas de Mamiquetla, el eclipse de Sol ocurre cuando el Malo (Diablo) le pega a Dios.

Con respecto a otros «agentes de eclipse», tal como ha denominado Michael Closs (1986) a aquellos seres que atacan o devoran al Sol o a la Luna -lo que provoca el fenómeno del eclipse-, dicho investigador (Closs 1986: 398, 400) señala que la información etnohistórica maya sobre los eclipses es consistente con la noción de que Venus actuó como agente de eclipse cosmológico. En este rol, la deidad venusina fue concebida como un jaguar; en la forma de una serpiente celeste, Quetzalcoatl, como Señor del Inframundo; y como una o varias hormigas, llamadas $x u b a b$ por los mayas yucatecos en el siglo XVII (Sánchez de Aguilar 1987: 83), y xulab por los mayas de Quintano Roo a fines de los 70 (Villa Rojas 1978: 447) . Los tzotziles coincidían en

\footnotetext{
5 Existen dos versiones respecto al ataque de estas hormigas contra el Sol: una es que toda una colonia se extiende sobre el astro; y otra, que el ataque es proferido por un monstruo de apariencia semejante a la de la reina de dichas hormigas (Villa Rojas 1978: 447).
} 
los años 60 en que el poslob, el eclipse, se personificaba en jaguar, en animales de mordedura ponzoñosa y en águila, cuya misión era el aniquilamiento de la humanidad (Guiteras 1996: 225-226).

Otras referencias contemporáneas a agentes de eclipse son los gusanos, quienes se comen a la Luna -la cual se repara a sí misma rápidamente-, según los nahuas de Milpa Alta (Madsen 1960: 169). Un nahua de Temoctla, del municipio de Chicontepec (Veracruz), señala que durante los tlamistonati (eclipses), el Sol se «pierde» al ser comido por un águila mediante picotazos (Cabrera 1991: 82, 84). Por último, para los tzutujiles de Santiago Atitlán, Sololá, en Guatemala, el eclipse solar ocurre cuando un enorme murciélago apaga la luz del astro (Villatoro et al. 1992: 6).

\section{Prácticas defensivas contra el eclipse solar}

Los informantes de Sahagún (Códice Florentino, lib. VII, en Sahagún 1969: 145) señalaron que cuando acontecía el eclipse de Sol, éste

«se muestra muy rojo; ya no permanece quieto; ya no está tranquilo; sólo está balanceándose. Se amarillece mucho. Enseguida hay bullicio; se inquieta el hombre; hay alboroto, hay trastorno, hay temor, hay llanto. Levantan el llanto los macehuales; se dan alaridos; hay gritos; hay grita; hay vocerío; hay clamor; se tienden los cascabeles. Son sacrificados albinos; son sacrificados cautivos. Se sangra la gente; se hacen pasar varas por las orejas y en los templos son cantados cantos floridos. Permanece el ruido; permanece la grita. Así se decía: 'Si acabase, si fuese comido el sol, todo oscurecerá para siempre, vendrán a bajar las tzitzimime, vendrán a comer gente'».

Este texto se puede dividir en cuatro partes. La primera corresponde a los cambios visibles que empieza a manifestar el astro solar debido al eclipse, los cuales pueden tener implicaciones simbólicas. En la segunda parte se describen las manifestaciones de miedo que expresaba la gente ante tal atentado contra el Sol. La tercera refiere a las prácticas culturales que desplegaron los nahuas con el fin de darle fortaleza al astro en su lucha contra las fuerzas nocturnas, y que también aminoraban el miedo; las expresiones que demostraban el miedo fungieron a la vez como prácticas paliativas. Por último, se señala el final funesto que sobrevendría si el Sol se sumiera definitivamente en las tinieblas: la destrucción de la humanidad.

Respecto a la primera parte, las expresiones «ya no permanece quieto; ya no está tranquilo; sólo está balanceándose» [aoc tlacamani; aoc tlacaca za mocuecueptimani] (Códice Florentino, lib. VII, en Sahagún 1969: 144-145), refieren a la desestabilidad del curso del astro por causa del eclipse, que en lugar de seguir un recorrido en línea recta empieza a balancearse; se puede decir, a deambular. En términos humanos, esto implicaba inmoralidad. El eclipse hacía que el Sol sufriera una pérdida de centralidad debido a su oscurecimiento. Esto recuerda algunas asociaciones simbólicas de los pueblos que peregrinan y adquieren temporalmente una condición chichimeca: el vagabundeo y andar en tinieblas (Anales de Cuauhtitlan 1945: 4). Una vez que un pueblo llegaba a asentarse de manera definitiva adquiría centralidad y abandonaba las tinieblas al salir el Sol (véase Graulich 1990: 16, 173, 288). 
Un ataque directo contra el Sol implicaba el mayor de todos los desequilibrios posibles: la inversión rotunda del orden, del cual era garante el astro, que generaba el regreso al tiempo primigenio donde la oscuridad y el caos reinaban y la humanidad no existía. La noche, de por sí, era un momento de tensión, pues la sobrenaturaleza nocturna estaba al acecho, pero este tiempo era totalmente previsto. En cambio, el anochecer repentino implicaba un resquebrajamiento del orden y la previsión (véanse Amador 1995: 316; Nájera 1995: 326). Tal contexto era sumamente propenso para que se creara una atmósfera de terror colectivo; sin embargo, los nahuas nunca sucumbieron ante el temor extremo. Con el fin de remediar esta crítica situación, fabricaron dispositivos de defensa, enmarcados dentro de su cosmovisión, dirigidos a proporcionarle fuerzas al Sol para que saliera bien librado del delicado trance que padecía durante un eclipse. En este sentido, fueron concebidos como prácticas propiciatorias. Al mismo tiempo, estos dispositivos culturales pretendían disminuir el peligro y el miedo intenso que experimentaba la población. Las prácticas propiciatorias fueron las siguientes:

1) Sacrificios humanos.

2) Autosacrificios.

3) Cantos floridos en los templos.

4) Producción de ruido y gritos en la población.

Los sacrificios humanos pueden ser considerados como ritos oficiales, mientras que los autosacrificios ritos individuales (Tena 1991: 73). Los primeros eran obligación del Estado y la casta sacerdotal, cuyos representantes eran los ejecutantes. Se buscaban hombres albinos (véase Mendieta 2002: t. I, lib. II, cap. XVI, 215) y cautivos para ser sacrificados. Albinos, porque debido a la blancura de su piel, se podía pensar que eran imágenes del Sol (Mendieta 2002: t. I, lib. II, cap. XVI, 215; véase Seler 1980: t. I, 156), con lo cual se trataría de reconstituirlo. Tal idea se asemeja mucho a una práctica maya ejecutada durante un eclipse solar que formaba parte de la profecía del katún 11 Ahau, que consistió en «hacer una pintura de la figura del Sol» una vez que éste había oscurecido (Libro de Chilam Balam de Chumayel 1985: 49).

Respecto a esta información, Martha Ilía Nájera (1995: 320) comenta que al atemorizarse el pueblo maya por suponer que el dios moría, se apresuraban a hacer una pintura que tendría como propósito «recrear de manera simbólica la imagen del sol que desaparecía y ayudar ritualmente a que vuelva a surgir».

A pesar de que los grupos nahuas conformaron una unidad cultural, entre ellos mantuvieron prácticas sacrificiales diferentes. Es así que cuando eclipsaba el Sol, los tlaxcaltecas sacrificaban «hombres bermejos», esto es, pelirrojos, pero de tono muy oscuro; y cuando había eclipse de Luna sacrificaban hombres y mujeres albinos (Muñoz Camargo 1998: 149). Esto contrasta con los nahuas del Centro de México, quienes sacrificaban albinos al astro diurno.

Esta elección de los sacrificados responde a un tipo de magia imitativa, la cual se funda en el principio de que «lo semejante produce lo semejante», o que los efectos semejan a sus causas (Frazer 1982: 34-35). Mediante el sacrificio de «hombres bermejos», debido a su color de cabello rojo, que era de naturaleza caliente, se trataba de compensar el calor y la energía que estaba perdiendo el Sol. Paralelamente, sacrificar albinos a la Luna respondía al mismo principio de semejanza: restituir la fuerza del 
astro, representada por su blancura, a través del sacrificio de personas de tez y cabello blancos. El hecho de que también se le sacrificara mujeres albinas se debe a la íntima relación que existía entre el astro lunar y lo femenino.

Fray Gerónimo de Mendieta (2002: t. I, lib. II, cap. XVI, 215) igualmente señala que se buscaban personas lampiñas para sacrificarlas durante un eclipse, seguramente de Sol. Lampiño en náhuatl es tlalhuatic, literalmente «nervudo» (López Austin 1996: t. I, 178), adjetivo que proviene de tlalhuatl, nervio, que en su forma abstracta, tlalhuayotl -literalmente «nerviosidad»-, refiere al sistema nervioso (Siméon 2002: 599). En el Vocabulario ... de Molina (2004: sección náhuatl-español, fol. 123v) también se encuentra la composición tlalhuatl ytetecuicaca, «pulso de la muñeca, o del brazo». El segundo vocablo proviene del verbo tetecuica, dar latidos (Molina 2004: sección náhuatl-español, fol. 106v), o latir; mientras que el sustantivo derivado es tetecuicaca, latidos, pero solamente se usa en forma posesiva: itetecuica, «sus latidos» (Siméon 2002: 514). Literalmente, tlalhuatl itetecuicaca significa «el latido de los nervios». A partir del hecho de que algunos nervios -además de ligamentos y tendones- se localizaban entre las coyunturas y se percibieran sus movimientos, se les atribuyó concentración de fuerza vital (López Austin 1996: t. I, 178). Con base en este análisis, se puede pensar que el sacrificio de lampiños al Sol -probablemente también a la Luna - tenía el objetivo de fortalecer sus nervios, que equivalía a reanimar el pulso del astro.

De manera general, con la acción de sacrificar cautivos se trataba de reactualizar el mito de la creación del Sol, específicamente el momento en el que los dioses debieron inmolarse para que el astro pudiera tener movimiento, tal como lo refiere Mendieta (2002: t. I, lib. II, cap. XVI, 215). Sangre y corazones eran el único alimento que el Sol demandó en el mito y que exigía en el tiempo humano para tener dinamismo. Así como diariamente se ofrendaba sangre para propiciar su recorrido, en los momentos críticos del astro debía potencializarse su ofrenda a través del sacrificio humano. Si un eclipse paralizaba el Sol (Anales de Cuauhtitlan 1945: 5) al menguar sus fuerzas, se trataba de restituirlas para que pudiera librarse del ataque voraz que sufría y retomara su curso ${ }^{6}$.

Según Lehmann (1968: 32), cuando había eclipse de Sol los mexicas buscaban inválidos, jorobados y otras personas con malformaciones para ser sacrificados, pues encarnaban al dios deforme Xolotl-Nanahuatzin, quien era considerado representante del sacrificio, activo y pasivo. En el mismo sentido, José Luis Rojas Martínez (The Aztec Empire: Catalogue... 2004: 31, fig. 124) señala que los mexicas «creían que la gente con deformidades, como los jorobados, los albinos, los siameses y, en particular, los enanos, eran hijos del Sol». Y cuando acontecía un eclipse solar, «ellos eran los primeros en ser sacrificados».

Si bien Motecuhzoma Xocoyotzin tenía la costumbre de mantener en sus palacios a personas deformes y albinas para que le sirvieran (Torquemada 1975: t. I, lib. III, cap. XXV, 408; Clavijero 2003: lib. V, 181), desconozco la fuente que sustenta la información anterior. De lo que sí tengo conocimiento es del sacrificio de albinos du-

6 Esto no se opone al movimiento deambulatorio del Sol al momento de eclipsarse, pues la inmovilización implica no poder seguir su curso normal en línea recta y sólo moverse de un lado a otro sobre su mismo punto. 
rante el eclipse de Sol, como se explicó arriba. No obstante, la posible inmolación de personas con patologías durante este evento mantiene cierta coherencia con el ritual y el mito. Narra fray Juan de Torquemada (1975: t. III, lib. VIII, cap. XII, 222; cap. XIII, 225) que durante la celebración dedicada al Sol, al terminar los cuatro días de ayuno que se hacían en su honor sacrificaban a cuatro cautivos nombrados chachame, traducido como «tontos» por el franciscano. Asimismo, señala que en esta misma fiesta inmolaban «leprosos y gente de males contagiosos» en el templo dedicado a Iztaccinteotl. Sin lugar a dudas, estos sacrificios rememoraban el sacrificio del dios Nanahuatzin, quien se arrojó al fuego para luego convertirse en Sol (Sahagún 2002: t. II, lib. VII, cap. II, 696).

Las afirmaciones de los anteriores estudiosos puede deberse a una extrapolación. En su vocabulario zapoteco, Juan de Córdova (citado por Seler 1980: t. I, 145) dedicó unas palabras a los eclipses. Señala que el eclipse de Sol era considerado el fin del mundo, y «dezian y creyan que los enanos eran hechos por mandado del sol, y que entonces como cosa suya los pedia. Y asi qualquiera que hallauan algun enano o enanos o hombres chiquitillos, o le tenían en su casa le mataba y sacrificaua...». Esta información, sin embargo, no es sustentada por las fuentes para el caso nahua.

Mediante un cruce de datos, podría pensarse que el sacrificio de personas deformes -siendo ellos la personificación de Nanahuatzin («el buboso») ${ }^{7}-$ durante el eclipse solar, pretendería recrear el nacimiento del astro, y con esta acción dotarlo de rejuvenecimiento y vitalidad. La reactualización del acontecimiento creador primigenio tendría la intención de neutralizar el evento de muerte.

Jacinto de la Serna (1987: 365-366) consignó una narración referente a un eclipse ocurrido en tiempos míticos, la cual remite al momento en que las pirámides del Sol y de la Luna fueron construidas. Se dice que una vez que se edificaron los templos a estos astros en Teotihuacan, los dioses ordenaron que se sacrificara gente en ellos. Asimismo, se previno el día y la hora de un eclipse solar. Días antes, los sacerdotes de dichos templos ordenaron que se anunciara que los dioses estaban muy enojados con su pueblo, y como castigo por sus pecados y el descuido de su culto, se habría de esconder la luz en un determinado día. Ante esto, los sacerdotes señalaron para dicho día un sacrificio de 12 jóvenes y 12 doncellas con el fin de aplacar su ira. Previo a esto ordenaron que tales jóvenes bailaran ante el Tempo del Sol, mientras que las doncellas lo harían frente al Templo de la Luna. Y así lo hicieron hasta el día del eclipse. Al ver los indios que faltaba la luz, arrojaron a los jóvenes a una hoguera dispuesta frente al templo del Sol, e hicieron lo propio con las doncellas: las arrojaron al fuego frente a su templo correspondiente. Poco después, el astro diurno empezó a resplandecer, de tal manera que los sacerdotes juzgaron que la ira de las deidades se había aplacado con aquellos sacrificios.

En este pasaje observamos que el eclipse solar es provocado por las transgresiones de los hombres cometidas contra los dioses en materia de culto. También destaca la asociación de lo masculino con el Sol y lo femenino con la Luna, reflejado tanto en

\footnotetext{
7 A partir de la iconografía, Eduard Seler (1980: t. I, 30, 55, 148) demostró que Xolotl es una advocación de Nanahuatzin. Y recordemos que el vocablo xolotl fue aplicado a los jorobados y enanos de quienes se hacía servir Motecuhzoma (Alvarado Tezozomoc 1944: cap. CVIII, 524), tanto por ser sus servidores - véase Molina 2004: sección náhuatl-español, fol. 160v-, como por su naturaleza deforme.
} 
el ordenamiento de los sacrificios como en la preparación ritual para este evento, que no consiste en ayunos, autosacrificios, ofrendas o rezos, sino en danzas. Por último, cabe resaltar el tipo de sacrificio efectuado, que recuerda precisamente la manera en que fue inmolado Nanahuatzin para convertirse en Sol. En general, toda la narración mantiene similitudes con el mito de la creación de los astros solar y lunar registrado por Sahagún (2002: t. II, lib. VII, cap. II, 694-696).

La información proporcionada por Serna igualmente nos habla de las importantes atribuciones que tuvieron los sacerdotes entre los nahuas, y que les confirió un gran reconocimiento social. Ellos conocían los designios y los deseos-necesidades de los dioses; la manera de persuadir su voluntad; los elementos necesarios de su ofrenda y el momento específico en que debían ofrecerse para establecer la comunicación con ellos. Asimismo, señalaban el estado de transgresión de los hombres al momento de culpabilizarlos por los infortunios sobre la Tierra, que eran la materialización de la ira divina. Estas facultades hacían de los sacerdotes unos excelentes previsores y eficaces manipuladores del ámbito sagrado. Tal manejo de lo sobrenatural fácilmente les proporcionó la conducción del pueblo, y no sólo en el orden religioso, sino también en el área del comportamiento y la moral, de tal manera que fueron los grandes aliados de la clase en el poder.

La obligación de reanimar al astro diurno era compartida por toda la población. Así, individualmente, «con gran temor», hombres, mujeres, ancianos y niños se punzaban las orejas por donde se hacían pasar varas, y también se extraían sangre de los brazos. Ésta era arrojada al Sol con los dedos, acción considerada «el más general sacrificio de todos» (Benavente 1996: cap. IX, 183; Las Casas 1967: t. II, lib. III, cap. CLXXIV, 201-202).

Lo anterior recuerda el ofrecimiento de sangre que se realizaba al astro y al fuego durante el rito llamado Tlazcaltiliztli, «evento de alimentar o hacer crecer», en el que la gente se extraía sangre de la orejas, la recibía en la uña del dedo pulgar o medio y la arrojaba hacia el Sol y el fuego. Esta ceremonia se efectuaba al finalizar la construcción de una casa o cuando reinaba el signo nahui ollin, signo del Sol (Sahagún 2002: t. I, apéndice del libro II, 287).

La ofrenda colectiva de sangre al astro evocaba el rito Tlazcaltiliztli, que como su nombre lo indica, pretendía nutrir y fortalecer a un Sol dañado por el ataque. Este evento se sumaba a las acciones sacrificiales de mayor envergadura, los holocaustos humanos, que encauzaban en un mismo objetivo: vivificar al astro solar.

Debido al total desconocimiento y terror que provocó el primer augurio (tetzahuitl) de la conquista, el de la columna de fuego (mixpanitl), se emularon las mismas medidas rituales defensivas desplegadas durante el eclipse solar: sacrificios humanos y autosacrificios, así como gritos, llantos y alaridos (Florentine Codex 1950-82: lib. XII, cap. I, 1; Sahagún 2002: t. III, lib. XII, cap. I, 1161).

Los cantos floridos en los templos y los gritos de los hombres son prácticas enmarcadas en un contexto guerrero, las cuales trataban de darle ánimos victoriosos al Sol para que triunfara en la batalla contra su agresor (véase Tena 1991: 73). Con dichas acciones posiblemente se trataba de imitar a los guerreros muertos en batalla que habitaban el cielo diurno, quienes tomaban sus armas para ir a recibir al Sol cada mañana. Con estruendo y gritos iban peleando delante de él hasta llevarlo al 
cenit (Sahagún 2002: t. II, lib. VI, cap. XXIX, 612). Graulich (1990: 243-244) señala que la producción de ruido originada por los guerreros habitantes del tonatiuh ichan («casa del Sol») con sus escudos, promovía la elevación del astro y su separación de la tierra. Dicho objetivo, proyectado al contexto de eclipse, pretendía impulsar al Sol en la continuación de su recorrido. Asimismo, los gritos de guerra alegraban al astro (Sahagún 1995: lib. VI, cap. XIV, fol. 60r, 117, 130). En algunos pueblos mayas de Huehuetenango y Sololá, los «atabaleros» suenan sus tunes y tambores tocando sones guerreros para ayudar al Sol durante su eclipse (Lara 1992: 12).

Por último, otra de las prácticas dispuestas por los nahuas para incrementar las fuerzas disminuidas del Sol y así ayudarlo en su trance, era la producción de ruido entre la población. Las fuentes concernientes a los nahuas no son muy explícitas con respecto a este punto, a diferencia de la información etnográfica. En general, se dice que la gente daba grandes gritos y lloros, los cuales tienen dos explicaciones: son manifestaciones del miedo ante el fin potencial del mundo (Muñoz Camargo 1998: 149; Mendieta 2002: I, lib. II, cap. XVI, 215); y son producidos para ayudar al Sol en su combate. Me voy a centrar en este segundo significado ${ }^{8}$.

A diferencia de la información nahua, Sánchez de Aguilar (1987: 83) registró entre los mayas yucatecos del siglo XVII información relativa al eclipse lunar, en la cual se observa la intención deliberada de producir ruido para ayudar al astro. Dice: «En los eclipses de la Luna usan por tradición de sus pasados hacer que sus perros aúllen, o lloren, pellizcándolos el cuerpo, o las orejas, y dan golpes en las tablas, y bancos, y puertas». Se promovía el ruido de cualquier fuente posible: humana, animal, y con ayuda de objetos. El tratamiento ritual ante un eclipse de Sol o de Luna fue muy parecido entre algunas culturas prehispánicas, tal como veremos en seguida respecto a indígenas contemporáneos.

Una joven nahua de Mamiquetla comenta que una vez hubo un eclipse solar y todas las mujeres se fueron a rezar a la iglesia. Les pegaban a los niños para que lloraran, hacían que los perros aullaran y los burros relincharan, con lo cual se ayudaba a Dios, el Sol, a que no le pegara el Malo (el Diablo), quien es el agente del eclipse.

En las comunidades nahuas del centro de Guerrero como Acatlán, Zitlala, Chilapa, Hueycatenango y Huitziltepec, entre otras, una práctica resultante de un eclipse de Sol es colgarles un bote viejo a niños y niñas de entre 6 a 12 años para que lo golpeen y suene por todas las calles del pueblo, de tal forma que puedan hacer revivir al astro. De no hacerlo, puede dejar de dar su luz, morir. Los nahuas de estas comunidades explican que el Sol es como un pollito. Cuando éste está a punto de morir se mete dentro de un bote de aluminio o de cualquier otro metal, el cual se golpea suavemente; con esta acción el pollito empieza a levantarse y a volver en sí. Dado que el Sol es mucho más grande que un pollo, se requiere que se golpeen la mayor cantidad de botes posibles para que pueda revivir, tal como se hace con el animalito (Ramírez 1991: 87-88). Aunque estos grupos le han dado una explicación un tanto diferente a la producción del ruido, la finalidad sigue siendo la misma: reanimar al Sol.

8 Sobre los gestos corporales producidos durante los contextos de miedo y su distinción genérica entre los nahuas, véase Echeverría y López 2013. 
Un tzotzil narró en los años 60 que durante el eclipse de Luna, mientras las mujeres lloraban y rezaban, los hombres «tocábamos palos y tablas haciendo ruido grande. Dejábamos sólo de tocar cuando se aclaraba la Luna...» (Guiteras 1996: 138)9. Aquí es todavía más explícita la producción intencional del ruido durante el tiempo que dura el eclipse, que cesa cuando éste acaba. Un dato a destacar es la diferencia genérica en la producción del ruido y otras acciones: las mujeres lloran y rezan; los hombres hacen ruido con objetos. Semejante distinción se observa entre los antiguos nahuas (Echeverría y López 2013). En el caso de Mamiquetla, las mujeres también son las que rezan. En San José Chacayá, en Sololá, cuya población es de origen cakchiquel y quiché, el eclipse ocurre cuando el Sol le pega a la Luna, o viceversa, por lo que uno de los dos huye. Para recuperar al astro desaparecido y ahuyentar al otro se produce mucho ruido (Villatoro et al. 1992: 7).

La producción de ruido durante un eclipse está enmarcado en un contexto de muerte, el del astro diurno, y de posible destrucción del mundo y de la humanidad. De acuerdo con un nahua de Xolotla, dichas destrucciones se caracterizan por el silencio, pues la señal que anunciará el fin del mundo, indica, será que el gallo no cantará en la madrugada ni los grillos. Los sonidos de estos animales pueden ser considerados como signo de vida.

El relato que proporciona el libro sagrado de los quichés sobre el momento anterior a la creación de la vida sobre la Tierra, complementa la información anterior y nos puede ayudar a delinear una hipótesis sobre la producción de ruido durante el evento del eclipse solar. Narra el Popol Vuh (2005: primera parte, cap. I, 23) que «todo estaba en suspenso, todo en calma, en silencio; todo inmóvil, callado... No había nada junto, que hiciera ruido, ni cosa alguna que se moviera, ni se agitara, ni hiciera ruido en el cielo... Solamente había inmovilidad y silencio en la oscuridad, en la noche».

Había ciertos momentos críticos determinados por acontecimientos naturales eventuales y extraordinarios considerados tetzahuitl, que podían predecir variadas desgracias, siendo el eclipse solar el que anunciaba el fin de la era presente. Al producir ruido, símbolo de vida y de creación, se intentaba evitar el regreso al tiempo primigenio y de intrascendencia, caracterizado por la inmovilidad, la oscuridad y el silencio, que, en suma, constituía la inversión del mundo de los humanos. La generación de sonido era una acción dirigida al Sol, garante del tiempo y la estabilidad cósmica. Al silencio y la oscuridad del eclipse se oponían los humanos con sus llantos, gritos y otros ruidos para hacer que el astro volviera a brillar ${ }^{10}$.

Otras acciones para ayudar al Sol que no mencionan las fuentes concernientes a los nahuas, son la producción de fogatas y arrojarle agua al astro, prácticas registradas por la etnografía. En cuanto a la primera, cabe la posibilidad de que se llevara a cabo en tiempos pretéritos. El fuego es un elemento estrechamente vinculado con el Sol en el pensamiento nahua antiguo, de tal manera que en el mito es el medio de transformación y renacimiento de la divinidad en el astro diurno. Solamente encontramos una

\footnotetext{
9 Los mayas de Quintana Roo tienen por costumbre durante los eclipses dar disparos en dirección al astro amenazado para ahuyentar al causante del eclipse (Villa Rojas 1978: 447-448).

10 Para Michel Graulich (1990: 243-244), el ruido producido durante un eclipse está dirigido a provocar una desunión entre el Sol y la Luna, tal como los guerreros en el más allá producen ruido con sus escudos cada mañana para hacer elevar al astro diurno y separarlo de la tierra.
} 
mención de sacrificio al fuego durante un eclipse, pero es una narración de carácter igualmente mítico.

Un informante nahua de Xolotla cuenta que durante un eclipse solar se encendían fogatas para pacificar al Sol y a la Luna que se encontraban en combate; y más bien se le trataba de ayudar a aquel astro en su lucha. Llegaba a tal grado la desesperación de la gente porque terminara el eclipse que incluso quemaban sus chozas. «Nuestros antepasados indígenas sentían alarma, sentían miedo, un pánico, que el día que eclipsa el Sol con la Luna haya un colapso. Los antepasados encendían sus casas, lo que sea, con tal de que aquella luz no se fuera, para que el Sol triunfara sobre la Luna y no cediera $[. .$.$] la oscuridad». De manera similar, otra xoloteca añade que durante este$ fenómeno, la gente quemaba plástico u hojas de plátano para hacer humo y que éste ascendiera con el objetivo de que finalizara el eclipse ${ }^{11}$.

En una localidad del municipio de Chicontepec, en la Huasteca veracruzana, un anciano nahua narró su vivencia durante un eclipse solar ocurrido décadas atrás. Señaló que al momento de empezar, la gente lo vio con miedo y decían que se iba a perder el mundo. Pararon de hacer sus cosas cuando el astro se tornó medio amarillento, mientras que los que tenían más edad «empezaron a hacer lumbre con bagazos de caña». El astro se iba poniendo cada vez más opaco. Esta lumbre era para que el Sol «agarra energías». Otros regaban agua hacia arriba para que éste se refrescara (Cabrera 1991: 82, 84).

Este último dato es muy interesante, pues si bien durante un eclipse solar el astro empieza a perder luminosidad, esto es, calor, por otro lado, también puede quemarse, tal como se describe en un eclipse de Sol en el Libro de Chilam Balam de Chumayel (1985: 49): «Y fue mordido el rostro del Sol. Y se oscureció y apagó su rostro. Y entonces se espantaron arriba. ' ¡Se ha quemado! ¡Ha muerto nuestro dios!', decían sus sacerdotes». Los nahuas de Tlacotepec refieren que cuando el astro lunar es eclipsado por el Sol, «se está quemando la luna» (Romero 2006: 53).

Una posible explicación de esto es la siguiente. Una creencia muy extendida entre los grupos étnicos de México es que cuando ocurre un eclipse, el Sol se come a la Luna o viceversa, lo cual se demuestra en el concepto indígena para referirse al fenómeno. Comer no sólo remite a la ingestión de alimentos, sino que también es una metáfora del acto sexual (Báez-Jorge 2008: 175; Lupo 1991: 231; Sedeño y Becerril 1985: 61), aspecto que queda confirmado en el náhuatl clásico con uno de los valores semánticos del verbo cua, comer, pues en su forma reflexiva mocua, «se comen», o su derivado nominal necualli, «el hecho de comerse», remiten al acto sexual (PuryToumi 1997: 145). En el náhuatl de Xolotla se conserva esta misma relación metafórica: mocua'que «se comen o se muerden»; y necualiztli, «el acto de comerse»-que también refiere a la comida- son maneras de llamar al acto sexual.

Esta equivalencia es indicada por un mito nahua prehispánico, en el que se cuenta que los mimixcoa Xiuhnel y Mimich se encontraron dos venados bicéfalos que posteriormente se convirtieron en mujeres. Una de ellas incitó a Xiuhnel a tener relaciones sexuales para después devorarlo (Leyenda de los Soles 2002: 189).

11 En la comunidad nahua de Tlacotepec de Díaz, ubicada en la Sierra Negra, al sur de Puebla, durante el eclipse solar de 1991 la gente hizo fogatas pero con el fin de alumbrarse (Romero 2006: 53). 
Con base en lo anterior, se puede pensar que durante un eclipse, los astros están teniendo relaciones sexuales, lo cual genera un calor intenso que puede llegar a quemar. El astro eclipsado será el que más resienta los efectos del sexo, será el que se queme. Con esto último hay que recordar la relación metafórica existente entre el sexo y el fuego en el pensamiento nahua prehispánico (Graulich 1983: 580-581; Olivier 2004: 470). Dicha relación es claramente expresada por Torquemada (1975: t. III, lib. X, cap. XXXIII, 419) al hablar del tlecuahuitl, que eran los palos para sacar fuego. Afirma que a éstos les llamaban tletlaxoni, que quiere decir «el que arroja o da fuego, que son dos palillos pequeños que puesto uno sobre otro y ludiendo [frotando] el macho en el que sirve de hembra, va sacando de él una harina muy molida y entre ella el fuego...». Más adelante explicaremos algunas asociaciones simbólicas concernientes a la relación sexual entre los astros.

\section{Consecuencias funestas del eclipse de Sol}

El principal peligro que se corría durante un eclipse solar prolongado era que descendieran las malévolas deidades femeninas tzitzimime y devoraran a los humanos, lo cual implicaba el fin del mundo. En una escala menor, este fenómeno desencadenaba consecuencias dañinas debido a la ausencia de los rayos solares o a una transformación perjudicial de los mismos al ser cubierto el astro.

Respecto a un eclipse ocurrido en 1611 registrado por Chimalpain en su Diario, señaló que mientras el Sol fuera comido habría mal tiempo, enfermedad, «viento malo» ${ }^{12}$. Se exhortó a que nadie mirara hacia arriba, que nadie anduviera por el camino sino que se encerraran en sus casas. También que nadie comiera, ni bebiera ni durmiera hasta que apareciera de nuevo el astro (Seminario de Traducción Náhuatl 1991: 78).

$\mathrm{Al}$ oscurecer el Sol por causa del eclipse menguaban sus fuerzas, lo que volvía dañino el calor que seguía emitiendo. De esta manera, repercutía en el tiempo, en la salud, en los alimentos e incluso en el sueño. Esto nos recuerda la creencia nahua de que durante su recorrido occidental, el Sol no ayudaba a fructificar la tierra (Durán 2002: t. II, tratado III, cap. I, 229). La energía disminuida del astro igualmente impedía la contención de ciertas fuerzas sobrenaturales peligrosas como el «viento malo», por ello se demandaba que toda la gente se refugiara en sus casas, que también evitaría que se viera directamente el eclipse, pues podía producir ceguera. De forma análoga, en una profecía de eclipse narrada en el Libro de Chilam Balam de Chumayel (1985: 50) se dice que por éste se «perderá todo sustento».

La idea de que los rayos solares en tiempo de eclipse son dañinos por una disminución de calor está muy bien expresada en la comunidad purépecha de San Andrés Tziróndaro. Aquí se dice que el eclipse puede afectar la cosecha al producir menos, $\mathrm{y}$ a las plantas en general, por lo que se recomienda amarrar listones rojos a las que se desee proteger de los efectos perjudiciales de dicho fenómeno. Igualmente, en

12 En algunos grupos indígenas actuales, el eclipse es una premonición divina que anuncia calamidades como guerra o enfermedades (Lupo 1991: 229-230; Villa Rojas 1978: 448, 451). 
Angahuan, también purépecha, se utiliza el color rojo para protegerse del eclipse (Pérez y Gómez 1991: 93-94). Debido a que este color es considerado de naturaleza caliente (véase López Austin en Sahagún 1969: 195-196), esta medida establece una compensación ante la falta de calor solar, lo cual elude su daño.

Asimismo, los rayos solares en dicho estado pueden causar graves enfermedades, razón por la que la gente se encierra en sus casas (Pérez y Gómez 1991: 93). Una anciana nahua de Xochiatipan, Hidalgo, relata que cuando el Sol eclipsó éste trajo gran enfermedad, expresada en calentura y dolor de cabeza, lo que provocó la muerte de muchas personas (Cabrera 1991: 84).

$\mathrm{Al}$ astro que siempre se le atribuye una intervención en la gestación y desarrollo del feto y de la vegetación es la Luna, que está íntimamente vinculada con las mujeres y su sexualidad (véase González Torres 1975: 85), y así fue entre los antiguos nahuas (Códice Vaticano Latino 3738 1964: t. III, lám. XXVI, 68; Códice TellerianoRemensis 1964: t. I, parte II, lám. XI, 198; Molina 2004: sección náhuatl-español, fol. $55 \mathrm{v})$. Pero también hay constancia de que el Sol estuvo involucrado en el desarrollo del nuevo ser. El astro era una de las fuentes por medio de la cual se incrementaba la fuerza del tonalli, entidad anímica que daba al individuo vigor, calor, valor y que permitía el crecimiento. De hecho, el vínculo entre el astro y el tonalli se refuerza en uno de los significados de éste: «calor solar» (López Austin 1996: t. I, 223, 225, 230). Dicho vínculo igualmente se hace patente en los momentos críticos del Sol. Es así que se creía que si una mujer embarazada veía un eclipse solar o lunar, su hijo nacería con labio leporino. La forma de prevenir tal daño era colocándole sobre su vientre una navaja de obsidiana (Códice Florentino, lib. V, en Sahagún 1969: 81).

Varios grupos indígenas contemporáneos igualmente asocian el Sol con los ámbitos de la generación humana y la sexualidad, tanto femenina como masculina, y la manera de evitar el perjuicio del eclipse solar sobre las embarazadas es muy similar a la que se ejecutaba entre los antiguos nahuas. Si una mujer encinta de Angahuan ve el Sol eclipsado el feto es dañado: puede nacer con deformaciones físicas como labio leporino, pies deformes o puede hablar de forma gangosa (Pérez y Gómez 1991: 93). En otra comunidad purépecha, Santa Fe de la Laguna, se cree que si un joven señala el eclipse con el dedo, corre el peligro de que al casarse pueda engendrar hijos deformes; mientras que si lo hace la muchacha, puede resultar estéril (Pérez y Gómez 1991: 93) ${ }^{13}$. Igualmente, si alguien se burla de una mujer encinta durante el transcurso del eclipse, el feto puede ser dañado; pero si aquélla es quien se burla de un hombre, éste no podrá procrear. El eclipse también puede perturbar el ciclo menstrual de las jóvenes; incluso puede hacer perder la virginidad (Pérez y Gómez 1991: 94).

Un eclipse solar puede trastocar hasta las actividades más cotidianas, como serían la preparación de los alimentos o la caza. En la población maya yucateca de Maxcanú, durante el eclipse solar de 1991 las mujeres no tortearon, pues suponían que al hacerlo las piedras del fogón quedarían demasiado suaves, lo cual se considera mal agüero. Mientras que los hombres no fueron a la milpa y mucho menos de caza, pues

13 De manera similar, los nahuas de Mamiquetla afirman que si se señala un arcoíris se caen las uñas, y si es una mujer encinta quien lo hace, aborta. 
los animales podrían adoptar una actitud muy distinta a la habitual y herir a los cazadores (Amador 1995: 314).

Como práctica defensiva contra la influencia dañina del Sol eclipsado, en algunos grupos nahuas de Guerrero las mujeres embarazas de inmediato se hacían de un objeto con filo como unas tijeras, un machete, un cuchillo o cualquier otro fierro filoso para introducírselo dentro de la ropa interior y pegárselo al vientre. El fin de esta acción es defender al feto de la fuerza nociva del eclipse y así evitar que nazca con la ausencia de un dedo, una oreja, un brazo, un pie o algún pedazo de otra parte del cuerpo (Ramírez 1991: 87) ${ }^{14}$. En la comunidad purépecha de Ihuatzio, la mujer embarazada también debe colocarse un cuchillo sobre el estómago con la punta hacia abajo para proteger al feto (Pérez y Gómez 1991: 94). Esta medida y su fin esperado se remontan a época precolombina, pero era efectuada durante el eclipse lunar (Códice Florentino, lib. VII, en Sahagún 1969: 139).

\section{Eclipse de Sol, ceguera, transgresión y castigo}

En este último apartado se bosqueja una hipótesis concerniente al eclipse solar que cae en el terreno de lo simbólico. Para ello, me remito en mayor medida a la información etnográfica, pero también se rescatan materiales históricos que igualmente ayudan a delinear dicha hipótesis. Aunque se presentan datos de diferentes grupos indígenas, todos ellos mantienen constantes, lo que permite su integración mediante un orden lógico con mayor facilidad. Como se señaló al inicio, las semejanzas en la información proveniente de grupos de distinta filiación étnica, así como en la información histórica, no refleja otra cosa que la unidad del pensamiento mesoamericano y su continuidad hasta nuestros días.

Los términos mayas que refieren al eclipse son tupa'an $u$ wich $k$ 'in y tupul $u$ wich $k^{\prime}$ in. Tupa'an significa «borrado, apagado» y tupa'an ich «el que está deslumbrado o encandilado y ciego que no ve»; mientras que tupul refiere a «apagarse, borrarse, desvanecerse, cegarse». Para indicar eclipse de luna se dice tupul u wich ú (Diccionario Maya Cordemex 1980: primera parte maya-español, 824-825). En la concepción maya yucateca, cuando la luz de los astros se desvanece por causa de un eclipse es como si éstos quedaran cegados, de manera que se establece la analogía entre la luz y la visión. Así, se elabora una proyección humana hacia el ámbito natural.

Por otro lado, a partir de prácticas contemporáneas realizadas durante el eclipse solar, se infiere que si se le ve directamente uno puede perder la vista. Por tal motivo, se acostumbra utilizar un recipiente con agua para ver el fenómeno a través de su reflejo en aquél ${ }^{15}$, con lo cual no se recibirán los efectos negativos del eclipse, según afirman los purépechas de Angahuan (Pérez y Gómez 1991: 94).

\footnotetext{
14 Las mujeres que han quedado embarazadas sin estar casadas son, por lo regular, descubiertas en estos momentos, porque es tan fuerte el mandato que también buscan algún objeto filoso o de hierro para metérselo en el vientre y así proteger a la criatura (Ramírez 1991: 87).

15 En el caso de los nahuas de Chicontepec se colocaban unas monedas dentro de un guacal con agua para que éstas reflejaran la luz solar durante el eclipse (Cabrera 1991: 84).
} 
La explicación tzotzil sobre la ceguera durante un eclipse de Sol fue proporcionada por el informante Manuel Arias Sojom en la década de los 60, quien comenta que durante el fenómeno, el chojchojotro -águila o gran halcón que se relaciona con las fuerzas destructoras y nocturnas- baja a sacarle los ojos a la gente, por lo que se los cubren con cera (Guiteras 1996: 169, 262).

Entre los antiguos nahuas se encuentra de manera indirecta esta relación. Ellos dejaron asentado que soñar con un eclipse solar auguraba ceguera -además de que la persona sería vendida- (Primeros Memoriales, en Sahagún 1969: 101). Por lo tanto, se infiere que soñar con dicho fenómeno equivalía a verlo directamente. Sin mayores rodeos, una mujer nahua de Xolotla indica que uno no puede voltear a ver un eclipse «porque ahí está la Luna que se está pegando con el Sol, están haciendo el Sol con la Luna, [y] ya no va uno volver a ver». Y si una mujer embarazada voltea a ver el eclipse, el bebé nacerá ciego.

Un dato interesante proporcionado por los nahuas de Mecayapan y Tatahuicapan, en Veracruz, es que nunca se debe mirar al Sol, su padre, porque implica un «insulto serio» que es castigado quitándoles la vista (Sedeño y Becerril 1985: 61). Aquí estamos frente a un registro diferente de la ceguera: el del castigo, y es a este punto al que he querido llegar. En efecto, uno puede quedarse ciego al contemplar un eclipse solar, pero la consecuencia real de observar dicho evento se explica mediante un hecho de carácter simbólico.

Retomemos la hipótesis planteada páginas atrás que enuncia que durante un eclipse los astros están teniendo relaciones sexuales. Ésta se sustenta a partir de dos relaciones metafóricas: el sexo y el acto de comer-en el discurso indígena se expresa que durante un eclipse el astro es comido-; y el sexo y el fuego - una fuente maya antigua indica que el Sol era quemado durante dicho fenómeno-.

Ahora, algunos grupos étnicos como los mayas de Quintana Roo (Villa Rojas 1978: 446), los nahuas de Veracruz (Sedeño y Becerril 1985: 61) y los otomíes (Galinier 1990: 531), consideran que Sol y Luna son padre y madre. De hecho, los nahuas de Tlaxcala del siglo XVI creían que los dos astros eran marido y mujer (Muñoz Camargo 1998: 148). Si una de las explicaciones del eclipse es que los astros están en combate, esto es, que uno se come al otro -como lo indica, por ejemplo, el concepto tonatiuh cualo para los nahuas-, tal acción puede ser concebida como la realización del acto sexual entre padre y madre.

A partir de lo anterior, interpreto que al contemplar un eclipse se presencia la escena primigenia: la relación sexual de los progenitores, lo cual implica una transgresión que es castigada con la ceguera. Varios datos confirman que ésta, o la disminución visual, es el castigo ante una transgresión sexual, como sería observar el acto carnal de los padres ${ }^{16}$. En un mito lacandón, Hachäkyum, el dios creador de los hombres y las

16 La etnografía ilustra bien la asociación entre el daño a los ojos y la falta sexual. En los años 60, en Tecospa, Milpa Alta, aquel hombre que tenía relaciones sexuales con una prostituta o que solamente pasaba por un campo donde una pareja estaba teniendo sexo extramarital, contaminaba a su esposa embarazada con aire de mujer (yeyecatlcihuatl) o «aire de basura», lo cual provocaba que su bebé naciera ciego (Madsen 1960: 191). También es común que la presencia de la persona sexualmente inmoral dañe con sus emanaciones a los recién nacidos, afectándoles los ojos (Madsen 1960: 191; Lewis 1968: 156). Me voy a extender un poco más para exponer la información que me fue proporcionada en Xolotla y Mamiquetla sobre la asociación que se viene tratando. El tlazolli es la emanación producida por la relación sexual que puede afectar principalmente 
estrellas, no quiso que los hombres vieran qué hacía en la lejanía con Nuestra Señora. Así que tomó los ojos de los hombres, los tostó en el comal y los volvió a colocar en las órbitas; por esta razón, los hombres quedaron reducidos en su capacidad visual (Bruce 1974: 128-132) ${ }^{17}$.

La ceguera atribuida al dios Iztlacoliuhqui en los códices indica su falta (Códice Telleriano-Remensis 1964: t. I, parte II, lám. XVIII, 212; Códice Vaticano Latino 3738 1964: t. III, lám. XXXVII, 90). En Tamoanchan, Tezcatlipoca sedujo a Xochiquetzal, Tlazolteotl, Cihuacoatl o Itzpapalotl, siendo el fruto de esta unión CinteotlItztlacoliuhqui (Olivier 2000: 340). En este caso, es el hijo el que carga con la transgresión sexual que cometió su padre ${ }^{18}$. Asimismo, entre los mayas yucatecos arrancar los ojos era «castigo antiguo para los amancebados» (Pérez 1866-1877, citado por Barthel 1968: 95, nota 54).

\section{Conclusiones}

En el contexto de eclipse solar se pusieron en práctica una serie de oposiciones que distinguieron un estado de muerte, caracterizado por el ataque al Sol, y un estado de vida, promovido por los sacerdotes y la población en general para restaurar el curso regular del astro. El eclipse, además de encarnar la oscuridad, fue sinónimo de inmovilidad, ausencia de sonido y, por lo tanto, de vida; mientras que los humanos, a través de determinadas prácticas rituales, pretendieron propiciar la luz, el dinamismo y la continuidad de la existencia. Cada una de las series de opuestos estuvo igualmente conformada por un estado emocional: al eclipse le correspondió el peligro y el terror, en tanto que las prácticas defensivas proporcionaban seguridad y esperanza. Sangre, corazones, cantos y gritos de guerra, y ruido en general, eran los elementos indispensables que le imprimían fuerzas y movimiento al Sol. Éstos pretendían disipar las tinieblas que amenazaban la vida sobre la Tierra.

El énfasis que se hace en la etnografía entre la deformación del feto y el eclipse solar puede remitirse a tiempos prehispánicos. Por un lado, en el mito mexica de la creación del Quinto Sol, un dios de rasgos deformes -ocasionado por las pústulas en su cuerpo-, Nanahuatzin, se convirtió en el astro diurno. Por otro lado, debido a la

\footnotetext{
a los más pequeños. Por ello, cuando la partera atiende un parto o cuando una persona visita a un bebé, deben evitar el sexo para no perjudicarlo. De no seguir esta precaución, la persona «sucia» le provocará ceguera. Este padecimiento es llamado ixtlazolcocoliztli o ixtlazolmiquiliztli, «enfermedad de basura de los ojos» y «muerte de basura de los ojos», respectivamente. Precisamente el tlazolli produce su afección. Asimismo, tlazolmicqui es el acto y efecto de que un niño o un adulto mueran de sarampión tras haber sido visitados por alguien con emanaciones sexuales.

17 Esta narración parece ser una versión de un antiguo mito quiché narrado en el Popol Vuh (2005: tercera parte, cap. II, 104-107), el cual asienta que los primeros cuatro hombres creados fueron dotados de tal inteligencia y conocimiento que les permitía saber todo, hecho que no les agradó a los dioses, pues los hombres debían ser solamente un reflejo de ellos, pero no iguales. Decidieron entonces echarles «vaho sobre los ojos, los cuales se empañaron como cuando se sopla sobre la luna de un espejo. Sus ojos se velaron y sólo pudieron ver lo que estaba cerca»; sólo un poco de la faz de la Tierra.

18 Esto nos recuerda la ceguera autoinfligida por Edipo al darse cuenta de la relación incestuosa que mantuvo con su madre, Yocasta (Sófocles 1999: 204). El contenido sexual de la ceguera fue identificado por Sigmund Freud (2000: 132) al señalar que funge como una castración simbólica.
} 
intervención directa del Sol en el desarrollo de la persona, cualquier alteración que sufriera el astro volvía perjudicial su influjo sobre ésta, o simplemente la interrupción violenta de los rayos solares la afectaba, principalmente a los seres más débiles: los fetos y los niños. Los primeros sufrían malformaciones mientras que los segundos, mutación animal.

Aunque en el registro histórico nahua el eclipse lunar es el evento mayormente relacionado con las deformaciones de los infantes, hay constancia de que si las mujeres embarazadas volteaban a ver al Sol eclipsado, sus hijos nacerían con labio leporino (Códice Florentino, lib. V, en Sahagún, 1969:81). Además del eclipse, otro atentado de gran envergadura que podía padecer el astro diurno era el no encendido del fuego durante la ceremonia de atadura de años, xiuhmolpilli, lo que ocasionaría que el Sol no volviera a salir. Asimismo, pronosticaba de forma análoga al eclipse solar la destrucción de la humanidad por acción de las tzitzimime. Igualmente se temía que los niños se transformaran en ratones si llegaran a quedarse dormidos (Florentine Codex 1950-82: lib. VII, cap. X, 27). Este peligro recuerda una de las prohibiciones señalada por Chimalpain durante el eclipse solar de 1611, citada anteriormente: que nadie durmiera hasta que apareciera nuevamente el astro. Cabe la posibilidad de que esta prohibición aludiera a la creencia de la mutación animal de los niños de no encenderse el fuego nuevo.

En el pensamiento mesoamericano, un mismo fenómeno puede tener diferentes explicaciones, no necesariamente relacionadas entre sí, por lo menos en el nivel más superficial. Al inicio del artículo se sostuvo que el principal agente del eclipse solar fue una fiera, especialmente el jaguar, y que la Luna, al ser el principal atacante del Sol en el antiguo pensamiento nahua, pudo ser concebida como aquel felino u algún otro tecuani al momento de devorar al astro. En otro registro de interpretación, propongo que el encuentro violento entre los astros durante el eclipse también simboliza -y simbolizó- su unión sexual. Esta propuesta parte de una doble metáfora: el acto de comer y el acto sexual; la producción del fuego y el sexo. La acción de observar el eclipse, es decir, el sexo entre los astros, es una transgresión que se castiga con la ceguera, lo que pone en evidencia la relación entre esta discapacidad y la falta sexual.

\section{Referencias bibliográficas}

Aguilera, Carmen y Jesús Galindo Trejo

1991 «Registro de eclipses en códices del Altiplano mexicano (1199-1531)», en Eclipses en México, pp. 61-67. México: Secretaría de Educación Pública - Instituto Nacional de Antropología e Historia - Instituto de Astrofísica, Óptica y Electrónica.

Alva Ixtlilxochitl, Fernando de

1997 «Sumaria relación de todas las cosas que han sucedido en la Nueva España...», en Obras Históricas, Edmundo O’Gorman, ed., t. I, pp. 262-393. México: Instituto Mexiquense de Cultura - Instituto de Investigaciones Históricas, Universidad Nacional Autónoma de México.

Alvarado Tezozomoc, Hernando

1944 Crónica Mexicana, Manuel Orozco y Berra, notas. México: Editorial Leyenda. 
Alvarez, Carlos

1983 «Esculturas de Teotenanco». Estudios de Cultura Náhuatl 16: 233-264.

Amador NARANJo, Ascensión

1995 «La desaparición del sol en Yucatán», en Religión y sociedad en el área maya, Carmen Varela, Juan Luis Bonor y Yolanda Fernández, eds., pp. 311-317. Madrid: Sociedad Española de Estudios Mayas - Instituto de Cooperación Iberoamericana - Caja Madrid.

Anales de Cuauhtitlan

1945 En Códice Chimalpopoca. Anales de Cuauhtitlan y Leyenda de los Soles, Primo Feliciano Velázquez, trad., pp. 3-68. México: Imprenta Universitaria, Instituto de Historia, Universidad Nacional Autónoma de México.

BÁEZ-JoRge, Félix

2008 El lugar de la captura (Simbolismo de la vagina telúrica en la cosmovisión mesoamericana). Veracruz: Editora del Gobierno del Estado de Veracruz.

BARTHEL, Thomas S.

1968 «Demonios murciélago mesoamericanos», en Traducciones mesoamericanistas, t. II, pp. 79-105. México: Sociedad Mexicana de Antropología.

Benavente, fray Toribio de

1996 Memoriales (Libro de oro, MS JGI 31), Nancy Joe Dyer, ed. México: El Colegio de México.

BRUCE, Robert D.

1974 El libro de Chan k'in. México: Instituto Nacional de Antropología e Historia.

Cabrera Vargas, Ma. del Refugio

1991 «Tlamistonati», en Eclipses en México, pp. 81-85. México: Secretaría de Educación Pública - Instituto Nacional de Antropología e Historia - Instituto de Astrofísica, Óptica y Electrónica.

Clavijero, Francisco Javier

2003 Historia antigua de México. México: Editorial Porrúa.

Closs, Michael P.

1986 «Cognitive Aspects of Ancient Maya Eclipse Theory», en World Archaeoastronomy, A. F. Aveni, ed., pp. 389-415. Cambridge: Cambridge University Press.

Códice Azcatitlan

1995 Michel Graulich, introducción y revisión; Robert H. Barlow, comentario; Leonardo López Luján, traducción. 2 tomos. París: Bibliothèque Nationale de France.

Códice Borgia

1980 Eduard Seler, comentarios; Mariana Frenk, traducción. México: Fondo de Cultura Económica.

\section{Códice de Huichapan}

2003 Lawrence Ecker, paleografía y traducción; Yolanda Lastra y Doris Bartholomew, eds. México: Instituto de Investigaciones Antropológicas. Universidad Nacional Autónoma de México.

Códice Telleriano-Remensis

1964 En Antigüedades de México, basadas en la recopilación de Lord Kingsborough, 
José Corona Núñez, ed., vol. I, pp. 151-337. México: Secretaria de Hacienda y Crédito Público.

Códice Vaticano Latino 3738

1964 En Antigüedades de México, basadas en la recopilación de Lord Kingsborough, José Corona Núñez, ed., vol. III, pp. 1-314. México: Secretaria de Hacienda y Crédito Público.

\section{Diccionario Maya Cordemex}

1980 Alfredo Barrera Vásquez, dir. Mérida: Ediciones Cordemex.

DurÁn, Fray Diego

2002 Historia de las Indias de Nueva España e islas de Tierra Firme [1581], Rosa Camelo y José Rubén Romero, estudio preliminar. México: Consejo Nacional para la Cultura y las Artes.

EcheverrRía García, Jaime y Miriam López HernÁndeZ

2013 «La expresión corporal del miedo entre los antiguos nahuas». Anales de Antropología 47: 143-166.

Escalona Ramos, Alberto

1940 Cronología y astronomía maya-mexica (con un anexo de historias indígenas). México: Editorial «FIDES».

Florentine Codex

Véase SAHAGÚN, 1950-82.

FRAZER, James George

1982 La rama dorada. Magia y religión. México: Fondo de Cultura Económica.

FreUd, Sigmund

2000 «Tótem y tabú. Algunas concordancias en la vida anímica de los salvajes y de los neuróticos (1913 [1912-13])», en Obras completas. Volumen XIII, Tótem y tabú y otras obras (1913-1914), pp. 1-164. Buenos Aires: Amorrortu.

GALINIER, Jacques

1990 La mitad del mundo. Cuerpo y cosmos en los rituales otomíes. México: Universidad Nacional Autónoma de México - CEMCA - Instituto Nacional Indigenista.

GonzÁLEZ Torres, Yólotl

1975 El culto a los astros entre los mexicas. México: SEP 80.

Graulich, Michel

1983 «Myths of Paradise Lost in pre-Hispanic Central Mexico». Current Anthropology 24 (5): 575-588.

1988 «Double Immolations in Ancient Mexican Sacrificial Ritual». History of Religions 27 (4): 393-404.

1990 Mitos y rituales del México antiguo. Madrid: Editorial Istmo.

Guiteras Holmes, Calixta

1996 Los peligros del alma. Visión del mundo de un tzotzil. México: Fondo de Cultura Económica.

Historia de los mexicanos por sus pinturas

2002 En Mitos e historias de los antiguos nahuas, Rafael Tena, ed., pp. 23-95. México: Consejo Nacional para la Cultura y las Artes. 
ICHON, Alain

1973 La religión de los totonacas de la Sierra. México: SEP - Instituto Nacional Indigenista.

Lara Figueroa, Celso A.

1992 «Tradiciones populares guatemaltecas sobre el eclipse de sol». La Tradición Popular 90: 8-12.

LAS CASAS, fray Bartolomé

1967 Apologética historia sumaria..., Edmundo O’Gorman, ed., 2 tomos. México: Instituto de Investigaciones Históricas, Universidad Nacional Autónoma de México.

LEHMANN, Walter

1968 «Eclipses solares, cometas y otros fenómenos en anales mexicanos», en Traducciones mesoamericanistas, t. II, pp. 31-43. México: Sociedad Mexicana de Antropología.

LEwIS, Oscar

1968 Tepoztlán, un pueblo de México. México: Editorial Joaquín Mortiz.

Leyenda de los Soles

2002 En Mitos e historias de los antiguos nahuas, Rafael Tena, ed., pp. 173-205. México: Consejo Nacional para la Cultura y las Artes.

Libro de Chilam Balam de Chumayel

1985 Mercedes de la Garza, ed. México: SEP.

López Austin, Alfredo

1996 Cuerpo humano e ideología. Las concepciones de los antiguos nahuas, 2 tomos. México: Instituto de Investigaciones Antropológicas, Universidad Nacional Autónoma de México.

LuPo, Alessandro

1991 «La etnoastronomía de los huaves de San Mateo del Mar, Oaxaca», en Arqueoastronomía y etnoastronomía en Mesoamérica, Johanna Broda, Stanislaw Iwaniszewski y Lucrecia Maupomé, eds., pp. 219-234. Serie de Historia de la Ciencia y la Tecnología 4. México: Instituto de Investigaciones Históricas, Universidad Nacional Autónoma de México.

MadSEN, William

1960 The Virgin's Children: Life in an Aztec Village Today. Austin: University of Texas Press.

Mendieta, fray Gerónimo de

2002 Historia eclesiástica indiana, Antonio Rubial, ed., t. I. México: Consejo Nacional para la Cultura y las Artes.

MolinA, fray Alonso

2004 Vocabulario en lengua castellana y mexicana y mexicana y castellana, Miguel León-Portilla, ed. México: Editorial Porrúa.

Muñoz CAmargo, Diego

1998 Historia de Tlaxcala (Ms. 210 de la Biblioteca Nacional de París), Luis Reyes, ed. Tlaxcala: Gobierno del Estado de México - Centro de Investigaciones y Estudios Superiores en Antropología Social - Universidad Autónoma de Tlaxcala. 
NÁJera Coronado, Martha Ilía

1995 «El temor a los eclipses entre comunidades mayas contemporáneas», en Religión y sociedad en el área maya, Carmen Varela, Juan Luis Bonor y Yolanda Fernández, eds., pp. 319-327. Madrid: Sociedad Española de Estudios Mayas - Instituto de Cooperación Iberoamericana - Caja Madrid.

Olivier Durand, Guilhem

2000 «¿Dios del maíz o dios del hielo? ¿Señor del pecado o señor de la justicia? Esbozo sobre la identidad de Itztlacoliuhqui», en Códices y Documentos sobre México, Tercer Simposio Internacional, Constanza Vega Sosa, ed., pp. 335-353. México: Instituto Nacional de Antropología e Historia.

2004 Tezcatlipoca. Burlas y metamorfosis de un dios azteca. México: Fondo de Cultura Económica.

PÉrez GonzÁlez, Benjamín y Lucas Gómez Bravo

1991 «Tata Jurhiata Angantani», en Eclipses en México, pp. 91-94. México: Secretaría de Educación Pública - Instituto Nacional de Antropología e Historia - Instituto de Astrofísica, Óptica y Electrónica.

Popol Vuh

2005 Adrián Recinos, ed. México: Fondo de Cultura Económica.

Pury-Toumi, Sybille de

1997 De palabras y maravillas: ensayo sobre la lengua y la cultura de los nahuas, Sierra Norte de Puebla. México: Consejo Nacional para la Cultura y las Artes CEMCA.

Ramírez Celestino, Alfredo

1991 «Nocua Tonahli!», en Eclipses en México, pp. 87-89. México: Secretaría de Educación Pública - Instituto Nacional de Antropología e Historia - Instituto de Astrofísica, Óptica y Electrónica.

Romero López, Laura Elena

2006 Cosmovisión, cuerpo y enfermedad. El espanto entre los nahuas de Tlacotepec de Díaz, Puebla. México: Instituto Nacional de Antropología e Historia.

SAHAGún, fray Bernardino de

1950-82 Florentine Codex, Charles E. Dibble y Arthur J. O. Anderson, ed. Sta. Fe: The School of American Research, University of Utah Press.

1969 Augurios y abusiones, Alfredo López Austin, ed. México: Instituto de Investigaciones Históricas, Universidad Nacional Autónoma de México.

1995 Los once discursos sobre la realeza. Libro sexto del Códice Florentino, Salvador Díaz Cíntora, ed. México: Coordinación de Humanidades, Universidad Nacional Autónoma de México.

1997 Primeros Memoriales, facsímil. Norman: University of Oklahoma Press.

2002 Historia general de las cosas de Nueva España, Alfredo López Austin y Josefina García Quintana, eds. 3 tomos. México: Consejo Nacional para la Cultura y las Artes.

Sánchez de Aguilar, Pedro

1987 «Informe contra los idólatras de Yucatán», en El alma encantada, Anales del Museo Nacional de México, pp. 13-122. México: Instituto Nacional Indigenista Fondo de Cultura Económica. 
SEDEÑo, Livia y María Elena BECERRIL

1985 Dos culturas y una infancia. Psicoanálisis de una etnia en peligro. México: Fondo de Cultura Económica.

SELER, Eduard

Véase Códice Borgia, 1980.

SEMinario de Traducción NÁHUATL

1991 «Tonatiuh Quallo: El Sol es comido. Eclipse de Sol del 10 de junio de 1611», en Eclipses en México, pp. 75-79. México: Secretaría de Educación Pública - Instituto Nacional de Antropología e Historia - Instituto de Astrofísica, Óptica y Electrónica.

SERNA, Jacinto de la

1987 «Manual de ministros de indios para el conocimiento de sus idolatrías, y extirpación de ellas» en El alma encantada, Anales del Museo Nacional de México, pp. 261-475. México: Instituto Nacional Indigenista - Fondo de Cultura Económica.

SIMÉON, Rémi

2002 Diccionario de la lengua náhuatl o mexicana. México: Siglo XXI Editores.

SÓFOCLES

1999 «Edipo, Rey», en Tragedias, pp. 145-213. Madrid: Edaf.

Solís Olguín, Felipe (ed.)

2005 The Aztec Empire. Catalogue of the Exhibition. Nueva York: Solomon R. Guggenheim Museum Publication.

TENA, Rafael

1991 «Conocimientos y creencias sobre los eclipses en el momento del contacto: las crónicas», en Eclipses en México, pp. 71-73. México: Secretaría de Educación Pública - Instituto Nacional de Antropología e Historia - Instituto de Astrofísica, Óptica y Electrónica.

The Aztec Empire: Catalogue of the Exhibition

2004 Felipe Solís, org. Nueva York: Guggenheim Museum Publications.

TORquEMADA, fray Juan de

1975 Monarquía Indiana ..., Seminario para el estudio de fuentes de tradición indígena, Miguel León-Portilla, coord., t. I y III. México: Instituto de Investigaciones Históricas, Universidad Nacional Autónoma de México.

Villa Rojas, Alfonso

1978 Los elegidos de Dios. Etnografía de los mayas de Quintana Roo. México: Instituto Nacional Indigenista.

Villatoro, Elba, Oscar Iván Maldonado y Daniel HernándeZ

1992 «Creencias y simbolismos acerca del eclipse en Guatemala». La Tradición Popular 90: 2-7. 